OPEN ACCESS

Edited by:

Marijn Lijffijt,

Baylor College of Medicine,

United States

Reviewed by:

Fiammetta Cosci,

University of Florence, Italy

Marta Torrens,

Parc de Salut Mar, Spain

*Correspondence:

Maria Rosaria Anna Muscatello mmuscatello@unime.it

Specialty section:

This article was submitted to

Psychopharmacology,

a section of the journal

Frontiers in Psychiatry

Received: 22 January 2019

Accepted: 25 September 2019

Published: 25 October 2019

Citation:

Muscatello MRA, Zoccali RA, Pandolfo G, Mangano P, Lorusso S,

Cedro C, Battaglia F, Spina E and Bruno $A$ (2019) Duloxetine in Psychiatric Disorders: Expansions Beyond Major Depression and Generalized Anxiety Disorder.

Front. Psychiatry 10:772.

doi: 10.3389/fpsyt.2019.00772

\section{Duloxetine in Psychiatric Disorders: Expansions Beyond Major Depression and Generalized Anxiety Disorder}

\author{
Maria Rosaria Anna Muscatello ${ }^{1 *}$, Rocco A. Zoccali', Gianluca Pandolfo', \\ Paolo Mangano ${ }^{2}$, Simona Lorusso ${ }^{3}$, Clemente Cedro ${ }^{1}$, Fortunato Battaglia ${ }^{4}$, \\ Edoardo Spina ${ }^{2}$ and Antonio Bruno ${ }^{1}$
}

${ }^{1}$ Department of Biomedical and Dental Sciences and Morphofunctional Imaging, University of Messina, Italy, ${ }^{2}$ Department of Clinical and Experimental Medicine, University of Messina, Italy, ${ }^{3}$ Department of Clinical Neurosciences, Villa San Benedetto Menni, Italy, ${ }^{4}$ Department of Medical Sciences, Neurology and Psychiatry, Hackensack Meridian School of Medicine, Seton Hall University, United States

Background: Duloxetine hydrochloride (DUL) is an antidepressant included in the pharmacological class of serotonin-norepinephrine reuptake inhibitors approved for the treatment of major depressive disorder, generalized anxiety disorder, diabetic peripheral neuropathic pain, fibromyalgia, and chronic musculoskeletal pain. The aim of this review was to elucidate current evidences on the use of DUL in the treatment of a variety of psychiatric disorders.

Methods: This systematic review was conducted according to PRISMA (Preferred Reporting Items for Systematic Reviews and Meta-Analyses) guidelines. PubMed database was searched from January 1, 2003, to September 30, 2018, using 11 key terms related to psychiatric disorders ("persistent depressive disorder," "dysthymic disorder," "bipolar disorder," "seasonal affective disorder," "obsessive-compulsive disorder," "social phobia," "panic disorder," "posttraumatic stress disorder," "schizophrenia," "eating disorders," "sexual disorders," "personality disorders") and one key term related to duloxetine ("duloxetine hydrochloride"). Article titles and abstracts were scanned to determine relevance to the topic. For additional studies, the authors also examined the reference lists of several of the included papers.

Results: Duloxetine may be an effective treatment for mood spectrum disorders, panic disorder, several symptom clusters of borderline personality, and as add-on drug in schizophrenia. Modest or conflicting results have been found for the efficacy of duloxetine in obsessive-compulsive disorder, posttraumatic stress disorder, eating, and sexual disorders.

Conclusion: Major limitations of the reviewed studies were short trial duration, small sample sizes, and the lack of control groups. Defining the potential role of DUL in the treatment of psychiatric disorders other than major depressive disorder and generalized anxiety disorder needs further randomized, placebo-controlled studies.

Keywords: duloxetine, psychiatric disorders, persistent depressive disorder, seasonal affective disorder, premenstrual dysphoric disorder, schizophrenia 


\section{INTRODUCTION}

Duloxetine hydrochloride (DUL) [LY248686; (+)-N-methyl3-(1-naphthalenyloxy)-2 thiophenepropanamine] is an antidepressant included in the pharmacological class of serotonin (5-HT)-norepinephrine (NE) reuptake inhibitors (SNRIs), a class that also comprises venlafaxine, desvenlafaxine, milnacipran, and levomilnacipran. Initially approved for the treatment of major depressive disorder (MDD) by the US Food and Drug Administration (FDA) in 2004 and, subsequently, by the Committee for Medicinal Products for Human Use in Europe, actually the drug is approved in a number of countries for the treatment of generalized anxiety disorder (GAD), diabetic peripheral neuropathic pain, fibromyalgia (FM), chronic musculoskeletal pain, and, in Europe, also for treating stress urinary incontinence (1). In addition, it has been proposed for patients with chemotherapy-induced neuropathies (2), and for chronic postsurgical pain (3).

The pharmacological profile of DUL has been characterized by a series of in vitro and in vivo experimental studies. In vitro, DUL preferentially inhibits 5-HT reuptake more than NE reuptake $(4,5)$; DUL binding capacity to the human 5-HT and NE transporters is 100 times more potent than venlafaxine, whereas its affinity for NE reuptake inhibition is lower than those of milnacipran and levomilnacipran $(6,7)$. DUL lacks affinity for monoamine receptors within the central nervous system and shows few effects on the histaminic H1, muscarinic, al-adrenergic, and opioid receptors (8). Chronic duloxetine treatment exerts a long-term modulatory effect on 5-HT and NE pathways, demonstrating no effect on basal 5-HT, NE, or dopamine levels in the cerebral cortex, a moderate effect on 5-HT and NE release in the hippocampus, and a substantial desensitization of terminal a2-heteroreceptors but not 5-HT1B receptors (9). Based on these evidences, it can be hypothesized that chronic DUL treatment involves adaptive changes of autoreceptor functions, similarly to what happens in chronic treatment with selective serotonin reuptake inhibitors (SSRIs) and noradrenaline reuptake inhibitors (NRIs), which fail to modify 5-HT and NE levels, respectively (10).

Other potential mechanisms linked to the antidepressant activity of DUL involve its effects on neurotrophin levels and neuronal plasticity. As well as other antidepressants, such as SSRIs and NRIs, chronic but not acute DUL treatment increases cortical and hippocampal expression of the mature form of brain-derived neurotropic factor (BDNF) that promotes neuronal survival and differentiation, differently from the precursor of BDNF (proBDNF), which increases programmed neuronal death $(11,12)$. Beyond its effect on BDNF, chronic DUL treatment augments the expression of the growth factor and immediate early gene activity-regulated cytoskeleton-associated protein (Arc) that has a substantial role in neural plasticity (13).

Since both 5-HT and NE monoamines are not only involved in the pathophysiology of depression, but also modulate ascending spinal nociceptive neurotransmission $v i a$ the descending inhibitory pain pathway (14), DUL shows analgesic properties in conditions of chronic pain (15). In addition, the inhibition of 5-HT and NE reuptake induced in the sacral spinal cord motor neurons that innervate the striated muscle of the urethral sphincter (16) makes DUL also effective in the treatment of stress urinary incontinence.
In summary, due to its clinical profile and mechanism of action, DUL may be a valuable option to treat disorders other than MDD and GAD. Therefore, the aim of this review was to elucidate current evidence on the use of DUL for the treatment of a variety of psychiatric disorders.

\section{PHARMACOKINETICS AND DRUG INTERACTIONS OF DULOXETINE}

After oral administration, DUL reaches the maximum concentration in plasma (Cmax) in approximately 6hours. Concomitant administration with a meal increases the time to peak absorption by 6 to 10 hours and decreases the area under the concentration-versus-time curve (AUC) by $10 \%$ (17). The estimated volume of distribution is $1,640 \mathrm{~L}$, bioavailability about $50 \%$, and protein binding (mainly to albumin or al-acidglycoprotein) up to $90 \%$ (17). Elimination of DUL (half-life of about 12 hours) occurs by hepatic biotransformation, via cytochrome P-450 (CYP) 1A2 and 2D6 isoforms, and by renal (70\%) and fecal (20\%) excretion. To date, none of the proposed major metabolites (any metabolite constituting $>1 \%$ of the total) has been shown pharmacologically active (18). Since DUL is extensively metabolized by the liver, any degree of hepatic insufficiency is a contraindication to treatment; in hepatopathic patients, after a single dose of $20 \mathrm{mg}$, mean plasma clearance was significantly reduced, AUC increased fivefold, and the half-life was threefold longer of that observed in patients without hepatic dysfunctions. DUL may also exacerbate preexisting chronic liver disease and interact with alcohol, potentially resulting in liver injury; thus, it should not be prescribed in these cases. Similarly, since renal excretion has a major role in the catabolism of DUL, subjects with a creatinine clearance of $<30 \mathrm{~mL} / \mathrm{min}$ and patients affected by moderate or severe renal impairment should be prescribed adjusted dosages of DUL and should be monitored closely during treatment. Drug interactions are possible: DUL has been shown to be both a substrate and a moderate inhibitor of CYP2D6, and therefore it can compete for the same isoenzymes with other substrates, such as tricyclic antidepressants, phenothiazines, and type 1C antiarrhythmics (19). In a similar way to other agents in the SNRI class, DUL may be involved in pharmacodynamic drug interactions; particularly, the combination of the drug with monoamine oxidase inhibitors is contraindicated, due to the possible development of a serotonin syndrome, a potentially life-threatening adverse event.

\section{TOLERABILITY AND SAFETY ISSUES}

The drug is generally safe and well tolerated across all approved indications in adults at doses ranging from 60 to $120 \mathrm{mg} /$ day, although potential therapeutic benefits of high doses of DUL are associated with emergent side effects, without significant symptoms reduction and final remission rates (20). The most commonly reported adverse reactions $(\geq 5 \%$ and at least twice the incidence of placebo patients) were nausea, dry mouth, somnolence, constipation, decreased appetite, and hyperhidrosis, which occurred mainly in the early stages of the assumption and 
disappeared after the first weeks of treatment (21). In the longerterm therapy (for at least 6 months to 1 year), frequent treatmentemergent adverse events observed in adult patients were palpitations, blurred vision, vertigo, weight gain/loss, chills/rigors, and pruritus (22). Regarding cardiovascular safety, a pooled analysis of clinical trials on MDD showed that DUL had modest effects on heart rate and blood pressure and no clinically meaningful effect on electrocardiogram (ECG) profiles; the cardiovascular effects of DUL were comparable with other antidepressants (23). However, it should be stressed that, in most studies, patients with unstable cardiovascular disease or preexisting ECG abnormalities were excluded, whereas the selected patients with cardiovascular disease had to be clinically stable and under treatment.

Regarding suicidality, a meta-analysis of differences in incidence and outcomes of suicidal behaviors during randomized trials of DUL versus placebo found no evidence of increase or decrease in risk of suicide-related events with DUL treatment (24). Whether antidepressant drugs with similar or different pharmacological profile can increase the risk of suicidality and aggressive behaviors is still a matter of debate, and discussing possible relationships among suicidality, antidepressant treatment, and MDD goes far beyond the aim of our review. However, based on a pooled analysis of trials of nine different antidepressants, which showed an increase in the suicidal ideation and behavior in children and adolescents with MDD for almost all drugs, the European Medicines Agency and the FDA required a black box warning about the use of DUL in children, adolescents, and young adults (25). Suicidal risk seems to be higher at treatment beginning, during dose-tapering phases, and after discontinuation of the drug.

Safety in overdose is one of the essential parameters that should guide antidepressants prescription, especially when considering that $50 \%$ of suicide attempts consist of drug overdose, and nearly $17 \%$ are made with the prescribed antidepressant (26). Overall, DUL is considered to be relatively safe in the case of overdose, but the possibility of fatal outcomes increases with concomitant assumption of multiple drugs. Symptoms of DUL overdose are somnolence, hypotension or hypertension, vomiting, tachycardia, syncope, serotonin syndrome, seizures, and coma. There is no specific antidote for DUL; thus, general measures for intoxication are recommended. Beyond monitoring of vital signs, gastric lavage and activated charcoal for limiting the absorption are suitable if performed soon after ingestion (25).

As also reported for other antidepressants, withdrawal reactions and discontinuation-emergent adverse events may occur after gradual or abrupt suspensions of DUL treatment; the rates of withdrawal symptoms, mainly nausea, ranged from $6 \%$ to $55 \%$ (27). This possibility should not be underestimated, and in the case of DUL, this issue is particularly important, since this agent is frequently prescribed in general care settings, for pain disorders, FM, and stress urinary incontinence.

\section{METHODS}

\section{Research Strategy}

This systematic review was conducted according to PRISMA (Preferred Reporting Items for Systematic Reviews and
Meta-Analyses) guidelines (28). PubMed database was searched from January 1, 2003, to September 30, 2018, using 11 key terms related to psychiatric disorders ("persistent depressive disorder," "dysthymic disorder," "bipolar disorder," "seasonal affective disorder," "obsessive-compulsive disorder," "social phobia," "panic disorder," "posttraumatic stress disorder," "schizophrenia," "eating disorders," "sexual disorders," "personality disorders") and one key term related to duloxetine ("duloxetine hydrochloride"). The electronic search strategy used for PubMed is described in Table $\mathbf{1 .}$

Articles have been selected by title and abstract; the entire article was read if title/abstract indicated that duloxetine was used for treating psychiatric disorders other than MDD and $\mathrm{GAD}$, and if the article potentially met the inclusion criteria. References of the selected articles were also examined in order to identify additional studies meeting the inclusion criteria.

\section{Study Selection}

Articles were included in the review according to the following inclusion criteria: English language, publication in peer reviewed journals, quantitative information on the use of duloxetine in psychiatric disorders other than MDD and GAD, and year of publication at least 2003. Articles were excluded by title, abstract, or full text for MDD and GAD diagnoses, also in comorbidity, and for irrelevance to the topic in question. Further exclusion criteria were review articles, editorial comments, case reports/ series, and animal model studies.

\section{Data Extraction}

Two authors (PM, SL) performed the initial search, independently reviewed and selected the references based on the inclusion and exclusion criteria, and clarified any disputes in the presence of a third expert reviewer (MRAM). The results were subsequently reevaluated by the auditors, and the salient results were shown. After having discarded duplicate articles, data derived from our research of articles included study author names, publication dates, study designs (i.e., open-label

TABLE 1 | List of search terms entered into the PubMed search engines for identification of the studies within the scope of this systematic review.

\begin{tabular}{ll}
\hline Number & Search terms \\
\hline 1 & PERSISTENT DEPRESSIVE DISORDER \\
2 & DYSTHYMIC DISORDER [all fields] \\
3 & BIPOLAR DISORDER [all fields] \\
4 & SEASONAL AFFECTIVE DISORDER [all fields] \\
5 & OBSESSIVE-COMPULSIVE DISORDER [all fields] \\
6 & SOCIAL PHOBIA [all fields] \\
7 & PANIC DISORDER [all fields] \\
8 & POSTTRAUMATIC STRESS DISORDER [all fields] \\
9 & SCHIZOPHRENIA [all fields] \\
10 & EATING DISORDERS [all fields] \\
11 & SEXUAL DISORDERS [all fields] \\
12 & PERSONALITY DISORDERS [all fields] \\
13 & DULOXETINE HYDROCLORIDE [all fields] \\
14 & 1 OR 2 OR 3 OR 4 OR 5 OR 6 OR 7 OR 8 OR 9 OR 10 OR 11 OR 12 \\
15 & 14 AND 13 \\
16 & ENglish [language] \\
17 & 2O03/01/01 to 2018/09/30 [publication date]
\end{tabular}


uncontrolled and randomized controlled trial), sample (case and control group), duloxetine regimen, active comparator regimen, primary outcome measures, and main efficacy results (response and remission rates, mean changes in outcome measures).

Principal outcome of interest included studies about duloxetine efficacy on psychopathological symptoms.

\section{RESULTS}

\section{Study Characteristics}

Figure 1 summarizes the flowchart of articles selected for the review. The search of PubMed database provided a total of 71 citations; no additional studies meeting inclusion criteria were identified by checking the reference list of the selected papers. After adjusting for duplicates, 65 records were screened. Of these, 8 studies were excluded because these were related to MDD and GAD diagnoses, 13 were irrelevant to the topic, 4 were reviews, and 14 were case report/series.

After the screening, a total of 19 studies assessing the use of duloxetine in psychiatric disorders other than MDD and GAD met the inclusion criteria and were included in the systematic review (Tables 2 and 3); in particular, 7 articles focused on other mood disorders, and 12 studies evaluated duloxetine efficacy in other psychiatric disorders (obsessive-compulsive disorder [OCD]/ panic disorder (PD)/posttraumatic stress disorder (PTSD)/eating disorders/schizophrenia/premature ejaculation [PE]/attentiondeficit/hyperactivity disorder [ADHD]/borderline personality disorder [BPD]).

\section{Use of Duloxetine in Other Mood Disorders}

The efficacy of DUL in patients with mood disorders other than MDD has been evaluated in seven clinical trials (Table 2).

The efficacy and safety of DUL on persistent depressive disorder (PDD), or dysthymia, or dysthymic disorder (DD) has been evaluated in four studies: two open-label trials and one randomized, controlled trial followed by an open extension study. The first, open-label, 12-week study (29), examined 24 adults with Diagnostic and Statistical Manual of Mental Disorders, Fourth Edition dysthymia alone or with concurrent major depression ("double depression") who received duloxetine 60
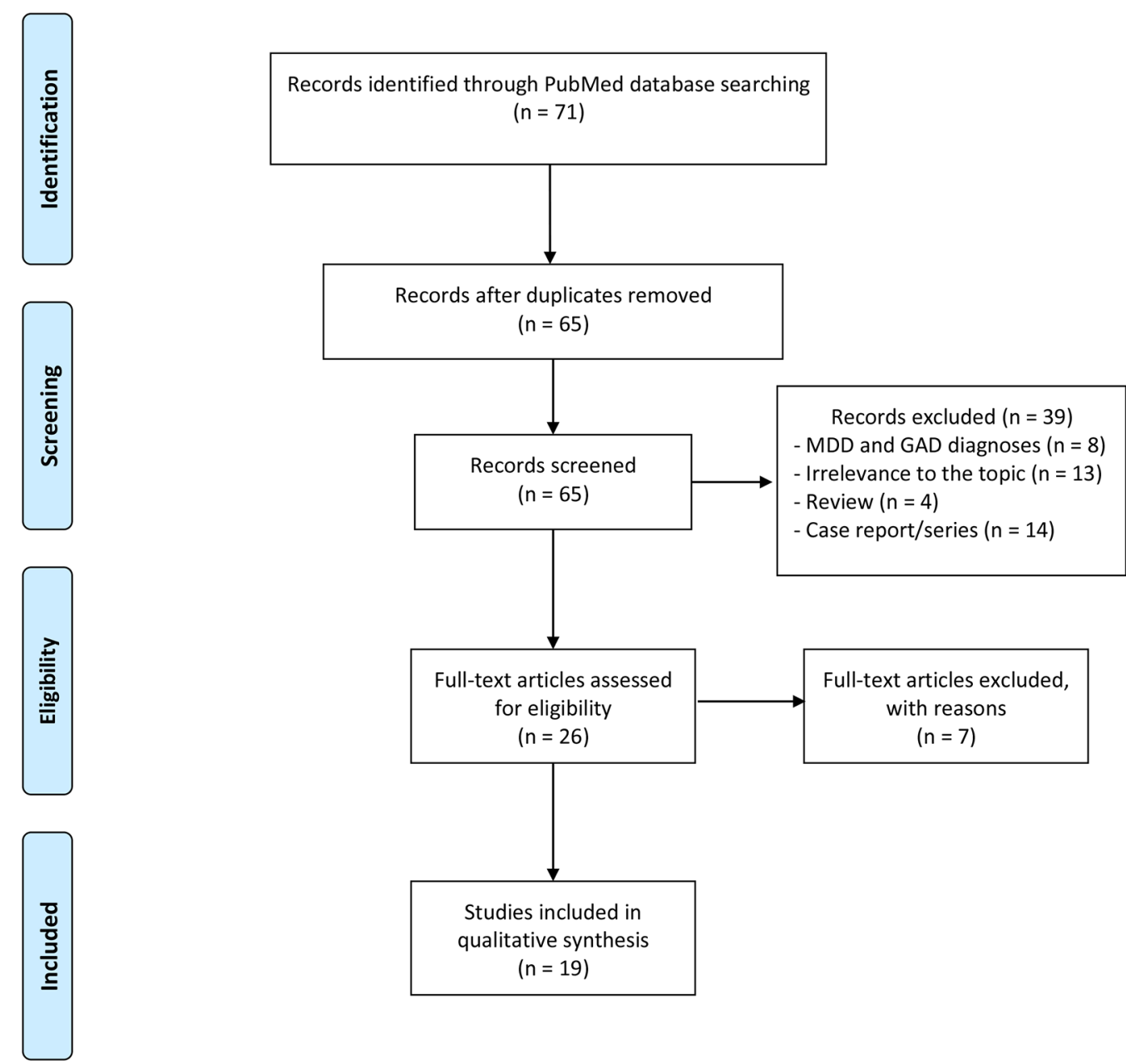

FIGURE 1 | Flow diagram of the literature selection process. 
TABLE 2 | Published efficacy trials of duloxetine in other mood disorders.

\begin{tabular}{|c|c|c|c|c|c|c|c|}
\hline $\begin{array}{l}\text { Authors/year of } \\
\text { publication }\end{array}$ & Study design & Trial duration & $\begin{array}{l}\text { Number } \\
\text { of patients }\end{array}$ & $\begin{array}{l}\text { Duloxetine } \\
\text { regimen }\end{array}$ & $\begin{array}{l}\text { Active } \\
\text { comparator } \\
\text { regimen }\end{array}$ & $\begin{array}{l}\text { Primary } \\
\text { outcome } \\
\text { measure }\end{array}$ & Main efficacy results \\
\hline \multicolumn{8}{|c|}{ Persistent depressive disorder } \\
\hline Koran et al., 2007 (29) & $\begin{array}{l}\text { Open-label, } \\
\text { uncontrolled }\end{array}$ & 12 weeks & 24 & 60-120 mg/day & NA & IDS-C & $\begin{array}{l}\text { IDS-C }(\mathrm{ITT}) \text { : response rate }=83 \% \text {; remission } \\
\text { rate }=79 \%\end{array}$ \\
\hline Kerner et al., 2014 (30) & $\begin{array}{l}\text { Open-label, } \\
\text { uncontrolled }\end{array}$ & 12 weeks & 30 & 20-120 mg/day & NA & HDRS & $\begin{array}{l}\text { HDRS }(I T T) \text { : response rate }=53.3 \% \text {; remission } \\
\text { rate }(I T T)=33.3 \% \text {; daily doses above } 60 \mathrm{mg} \\
\text { were associated with greater improvement } \\
\text { and well tolerated }\end{array}$ \\
\hline Hellerstein et al., 2012 (31) & $\begin{array}{l}\text { Randomized, } \\
\text { double-blind, } \\
\text { placebo-controlled }\end{array}$ & 10 weeks & 65 & 30-120 mg/day & NA/PI & HDRS & $\begin{array}{l}\text { HDRS: response rate DUL vs. } P I=65.5 \% \\
\text { vs. } 25.0 \%(p=0.003) ; \text { remission rate DUL } \\
\text { vs. } P I=55.2 \% \text { vs. } 14.3 \%(p=0.002)\end{array}$ \\
\hline Hellerstein et al., 2017 (32) & $\begin{array}{l}\text { Open-label, } \\
\text { observational }\end{array}$ & 12 weeks & $19 \mathrm{D} 24 \mathrm{PI} \rightarrow \mathrm{D}$ & 30-120 mg/day & NA & HDRS & $\begin{array}{l}\text { Patients continuing DUL: response criteria = } \\
84 \% \text {, remission criteria }=63 \% . \text { Patients } \\
\text { initially PI: response criteria }=83 \% \text {, remission } \\
\text { criteria }=62 \%\end{array}$ \\
\hline \multicolumn{8}{|l|}{ Seasonal affective disorder } \\
\hline Pjirek et al., 2008 (33) & $\begin{array}{l}\text { Open-label, } \\
\text { uncontrolled }\end{array}$ & 8 weeks & 26 & 60-120 mg/day & NA & SIGH-SAD & $\begin{array}{l}\text { SIGH-SAD }(\mathrm{ITT}) \text { : response rate = 80.8\%; } \\
\text { remission rate }=76.9 \%\end{array}$ \\
\hline \multicolumn{8}{|c|}{ Premenstrual dysphoric disorder } \\
\hline Mazza et al., 2008 (34) & $\begin{array}{l}\text { Open-label, } \\
\text { uncontrolled }\end{array}$ & $\begin{array}{l}\text { Two menstrual } \\
\text { cycles }\end{array}$ & 55 & 60 mg/day & NA & VAS-Mood & VAS-Mood: response rate $=78 \%$ \\
\hline Ramos et al., 2009 (35) & $\begin{array}{l}\text { Single-blind, } \\
\text { uncontrolled }\end{array}$ & $\begin{array}{l}\text { Three menstrual } \\
\text { cycles }\end{array}$ & 20 & 60 mg/day & $\mathrm{NA} / \mathrm{PI}$ & DRSP & DRSP (ITT): response rate = 65\% \\
\hline
\end{tabular}

DUL, duloxetine; NA, not available; PI, placebo; IDS-C, Inventory for Depressive Symptomatology; HDRS, Hamilton Depression Rating Scale; SIGH-SAD, Structured Interview Guide for the Hamilton Rating Scale-SAD version; VAS-Mood, visual analog scale-mood; DRSP, Daily Record of Severity of Problems; ITT, intent-to-treat.

$\mathrm{mg} /$ day for 6 weeks, increased to $120 \mathrm{mg}$ /day for the remainder of the 12-week trial for those who showed a partial treatment response. Outcome measure was the clinician-rated Inventory for Depressive Symptomatology (IDS-C), whose mean scores significantly decreased from baseline to endpoint under DUL treatment. Among study completers, the IDS-C response rate was $89 \%(17 / 19)$, and the remission rate $84 \%(16 / 19)$; five subjects (21\%) dropped out for unwanted side effects.

A more recent open-label, 12-week trial (30) evaluated the efficacy of duloxetine for DD in 30 older adults (mean age $=70.7$ years; completers $=19$ ). Duloxetine was prescribed at flexible doses, starting from $20 \mathrm{mg} /$ day (first week) up to $120 \mathrm{mg}$ daily. Depressive symptoms improved with duloxetine as assessed by the 24-item Hamilton Depression Rating Scale (HDRS) and the more specific Cornell Dysthymia Rating Scale (CDRS); response $(\geq 50 \%$ decrease in HDRS scores with a Clinical Global Impression [CGI] score of "much improved") rate was 53\%, and remission rate $33.3 \%$, with remission defined as a final HDRS score $\leq 6$. Out of the total number of 11 dropouts during the study, $16.7 \%$ were due to adverse effects (dry mouth, weakness, sexual dysfunction, and constipation).

The double-blind, randomized 10-week trial examined the efficacy of DUL (dosage range, 30-120 mg/day) on DD or depression not otherwise specified in a sample of 57 patients (31). After 10 weeks, duloxetine-treated subjects had significantly lower scores than placebo-treated subjects on the primary outcome measure, the 24-item HDRS $(P=0.003)$, and on secondary measures (CDRS, CGI), whereas no effect of DUL treatment was seen on Beck Depression Inventory (BDI), Global Assessment of Functioning, and Social Adjustment Scale (SAS). The response rate was $65.5 \%$ for DUL versus $25.0 \%$ for placebo $\left(\chi_{1}^{2}=9.43, P=\right.$ 0.003 ), and the remission rate was $55.2 \%$ for DUL versus $14.3 \%$ for placebo $\left(\chi_{1}^{2}=10.46, P=0.002\right)$. On the basis of the observed residual deficits in functioning even after clinical symptoms remission, the authors designed an additional 12-week continuation phase of the study, in which participants (DUL group $\mathrm{n}=19$ ) were provided with open DUL treatment, including those initially assigned to placebo $(n=24)$ (32). Sustained symptoms improvement was seen in patients continuing DUL, with $84 \%$ meeting response and $63 \%$ remission criteria at endpoint (week 22). Patients switching from placebo to DUL showed similarly high levels of response (83\%) and remission (62\%) at endpoint. Nevertheless, in the longer term, DUL-continuation patients improved only modestly on social and cognitive functioning, with $66.7 \%$ of patients persisting in the impaired range of functioning according to the SAS.

Only one open-label study examined DUL efficacy and tolerability in 26 subjects affected by seasonal affective disorder (SAD) (33). All participants were assessed by the Structured Interview Guide for the Hamilton Rating Scale-SAD version (SIGH-SAD), the Clinical Global Impression of Severity (CGI-S), the Clinical Global Impression of Improvement (CGI-I), the CGI Efficacy Index, the Social Adaptation Self-evaluation Scale, and the Sheehan Disability Scale (SDS) and received 60 to $120 \mathrm{mg} /$ day of DUL for 8weeks. Primary outcome variables were SIGH-SAD total score; response was defined as a reduction of SIGH-SAD total score of more than $50 \%$ from baseline score, and remission was a SIGH-SAD total score of 7 or lower. Results showed that DUL treatment (21 patients were treated with $60 \mathrm{mg}$, and 5 received $120 \mathrm{mg})$ had a significant effect on SIGH-SAD total score $\left(F_{1.74}=\right.$ $55.20, P<0.001)$. At endpoint, 21 patients $(80.8 \%)$ had responded 
TABLE 3 | Published efficacy trials of duloxetine in other psychiatric disorders.

\begin{tabular}{|c|c|c|c|c|c|c|c|}
\hline $\begin{array}{l}\text { Authors/year of } \\
\text { publication }\end{array}$ & Study design & $\begin{array}{l}\text { Trial } \\
\text { duration }\end{array}$ & $\begin{array}{l}\text { Number } \\
\text { of patients }\end{array}$ & $\begin{array}{l}\text { Duloxetine } \\
\text { regimen }\end{array}$ & $\begin{array}{l}\text { Active } \\
\text { comparator } \\
\text { regimen }\end{array}$ & $\begin{array}{l}\text { Primary } \\
\text { outcome } \\
\text { measure }\end{array}$ & Main efficacy results \\
\hline \multicolumn{8}{|c|}{ Obsessive-compulsive disorder } \\
\hline Dougherty et al., 2015 (36) & $\begin{array}{l}\text { Open-label, } \\
\text { uncontrolled }\end{array}$ & 17 weeks & 20 & 60-120 mg/day & NA & Y-BOCS & $\begin{array}{l}\text { Y-BOCS (ITT): full responders = 35\%; } \\
\text { nonresponders }=45 \%\end{array}$ \\
\hline Mowla et al., 2016 (37) & $\begin{array}{l}\text { Randomized, } \\
\text { double-blind }\end{array}$ & 8 weeks & 46 & 20-60 mg/day & $\begin{array}{l}\text { Sertraline 50- } \\
200 \mathrm{mg} / \text { day }\end{array}$ & Y-BOCS & $\begin{array}{l}\text { Y-BOCS: DUL response rate }=62.5 \% \text {; S response } \\
\text { rate }=62.5 \%\end{array}$ \\
\hline \multicolumn{8}{|l|}{ Panic disorder } \\
\hline Simon et al., 2009 (38) & $\begin{array}{l}\text { Open-label, } \\
\text { uncontrolled }\end{array}$ & 8 weeks & 15 & 30-120 mg/day & NA & PDSS & $\begin{array}{l}\text { PDSS: mean (SD) Baseline vs. endpoint }=14.2 \\
\text { (4.2) vs. } 9.13(5.2)(P=0.001)\end{array}$ \\
\hline \multicolumn{8}{|l|}{ Posttraumatic stress disorder } \\
\hline Villarreal et al., 2010 (39) & $\begin{array}{l}\text { Open-label, } \\
\text { uncontrolled }\end{array}$ & 12 weeks & 20 & 30-120 mg/day & NA & CAPS & $\begin{array}{l}\text { CAPS }(\mathrm{ITT}) \text { : response rate }=45 \% \text {; remission } \\
\text { rate }=5 \%\end{array}$ \\
\hline \multicolumn{8}{|l|}{ Eating Disorders } \\
\hline Leombruni et al., 2009 (40) & $\begin{array}{l}\text { Open-label, } \\
\text { uncontrolled }\end{array}$ & 12 weeks & 45 & 60-120 mg/day & NA & BES & $\begin{array}{l}\text { BES (ITT): mean (SD) baseline vs. endpoint }=28.8 \\
\text { (8.2) vs. } 22.9(11.0)(P=0.001)\end{array}$ \\
\hline $\begin{array}{l}\text { Guerdjikova et al., } 2012 \\
(41)\end{array}$ & $\begin{array}{l}\text { Randomized, } \\
\text { double-blind, } \\
\text { placebo-controlled }\end{array}$ & 12 weeks & 40 & 30-120 mg/day & NA/PI & $\begin{array}{l}\text { Binge day } \\
\text { frequency }\end{array}$ & $\begin{array}{l}\text { Binge day frequency: remission rate DUL vs. } \mathrm{Pl}= \\
56 \% \text { vs. } 30 \%(P=0.09)\end{array}$ \\
\hline \multicolumn{8}{|l|}{ Schizophrenia } \\
\hline Micò et al., 2011 (42) & $\begin{array}{l}\text { Randomized, } \\
\text { double-blind, } \\
\text { placebo-controlled } \\
\text { augmentation } \\
\text { study (clozapine) }\end{array}$ & 16 weeks & 40 & $60 \mathrm{mg} /$ day & NA/PI & PANSS & $\begin{array}{l}\text { PANSS change (ITT): T mean (SD) DUL vs. } P I= \\
-15.9(14.9) \text { vs. } 0.8(3.9)(P<0.0001) ; \mathrm{N} \text { mean } \\
\text { (SD) DUL vs. } \mathrm{PI}=-4.4(3.1) \text { vs. } 0.7(1.9)(P< \\
0.0001) ; \text { GP mean (SD) DUL vs. } \mathrm{PI}=-10.4(11.7) \\
\text { vs. } 0.3(2.6)(P<0.0001)\end{array}$ \\
\hline Nikbakhat et al., 2016 (43) & $\begin{array}{l}\text { Randomized, } \\
\text { double-blind, } \\
\text { placebo-controlled } \\
\text { augmentation } \\
\text { study (risperidone) }\end{array}$ & 8 weeks & 64 & 60 mg/day & NA/PI & PANSS & $\begin{array}{l}\text { PANSS scores: T mean (SD) DUL vs. } \mathrm{PI}=24.6 \\
\text { (7.2) vs. } 19.3(3.4)(P=0.001) ; \mathrm{N} \text { mean }(\mathrm{SD}) \mathrm{DUL} \\
\text { vs. } \mathrm{PI}=6.1(2.0) \text { vs. } 4.1(1.1)(P=0.001) ; \mathrm{GP} \\
\text { mean (SD) DUL vs. } \mathrm{PI}=9.9(2.9) \text { vs. } 7.9(1.2) \\
(P=0.001)\end{array}$ \\
\hline \multicolumn{8}{|l|}{ Premature ejaculation } \\
\hline Athanasios et al., 2007 (44) & $\begin{array}{l}\text { Randomized, } \\
\text { double-blind, } \\
\text { placebo-controlled }\end{array}$ & 12 weeks & 20 & 80 mg/day & NA/PI & IELT & $\begin{array}{l}\text { IELT: mean time (SD) DUL vs. placebo }=129.34 \\
(67.5) \text { vs. } 38.61(16.9)(P<0.001)\end{array}$ \\
\hline Ozcan et al., 2015 (45) & $\begin{array}{l}\text { Randomized, } \\
\text { double-blind }\end{array}$ & 4 weeks & 80 & 40 mg/day & $\begin{array}{l}\text { Paroxetine } \\
20 \mathrm{mg} / \text { day }\end{array}$ & IELT & $\begin{array}{l}\text { IELT: increasing rate DUL vs. } P=117 \% \text { vs. } 126 \% \\
(P>0.05)\end{array}$ \\
\hline \multicolumn{8}{|c|}{ Attention-deficit/hyperactivity disorder } \\
\hline Bilodeau et al., 2014 (46) & $\begin{array}{l}\text { Randomized, } \\
\text { double-blind, } \\
\text { placebo-controlled }\end{array}$ & 6 weeks & 30 & 60 mg/day & NA/PI & $\begin{array}{l}\text { CAARS- } \\
\text { Inv : SV }\end{array}$ & $\begin{array}{l}\text { CAARS-Inv : SV: mean DUL vs. PI = } 25.67 \text { vs. } \\
31.33(P>0.05)\end{array}$ \\
\hline \multicolumn{8}{|l|}{ Borderline personality disorder } \\
\hline Bellino et al., 2010 (47) & $\begin{array}{l}\text { Open-label, } \\
\text { uncontrolled }\end{array}$ & 12 weeks & 18 & $60 \mathrm{mg} /$ day & NA & BPDSI & $\begin{array}{l}\text { BPDSI: significant improvement in total score } \\
(P=0.001) \text {, "Impulsivity" ( } P=0.028) \text {, "outbursts } \\
\text { of anger" ( } P=0.0005) \text {, "affective instability" ( } P= \\
\text { 0.001) }\end{array}$ \\
\hline
\end{tabular}

DUL, duloxetine; S, sertraline; P, paroxetine; PI, placebo; NA, not available; Y-BOCS, Yale-Brown Obsessive Compulsive Scale; PDSS, Panic Disorder Severity Scale; CAPS, Clinician-Administered PTSD Scale; PCL-C, PTSD Checklist; BES, Binge Eating Scale; PANSS (T, P, N, GP): Positive and Negative Syndrome Scale (total score, positive, negative, and general psychopathology subscales); IELT, intravaginal ejaculation latency time; CAARS-Inv : SV, Conners' Adult ADHD Rating Scale-Investigator Report: Screening Version; BPDSI, Borderline Personality Disorder Severity Index; ITT, intent-to-treat.

to DUL treatment, and 20 patients $(76.9 \%)$ had experienced remission according to the above defined criteria. Patients showed marked improvement on secondary outcome measures of social functioning. Fifty-five treatment-emergent adverse events were reported during the trial, $26(47.3 \%)$ of which were classified as mild (palpitations, tremors, sedation, loss of weight), $21(38.2 \%)$ as moderate (headache, insomnia, inner tension), and 8 (14.5\%) as severe (dry mouth, hyperhidrosis, constipation).

Two studies have evaluated DUL efficacy and safety on premenstrual dysphoric disorder (PMDD). The first was an open-label, fixed-dose (60 mg/day) study (34) on a sample of 55 subjects ( 50 completers). All subjects were assessed by a visual analog scale (VAS) recording 11 mood symptoms (primary outcome measure), the HDRS, the Hamilton Anxiety Rating Scale (HARS), the Zung Self-rating Scale for Depression, and the CGI-S. DUL, administered for two menstrual cycles, was effective during the first cycle in reducing mood symptoms, with 39 subjects (78\%) meeting criteria for treatment response, defined as at least 50\% reduction in luteal VAS mood score from baseline to endpoint. A concomitant improvement in anxiety 
symptoms and in general functioning was seen. Adverse events during the treatment phase were nausea (three subjects [6\%]), insomnia (two subjects [4\%]), and poor appetite (two subjects [4\%]). A single-blind, uncontrolled, fixed-dose (60 mg/day) trial evaluated the effect of DUL on 20 patients ( 15 completers) with PMDD (35). All patients were rated with the short form of Daily Record of Severity of Problems (DRSP), a 14-item patient-rated scale that incorporates all symptoms listed in the Diagnostic and Statistical Manual of Mental Disorders, Fourth Edition, Text Revision diagnostic criteria for PMDD, the 17-item HDRS, CGIS, CGI-I, SDS, and the short form of the Quality of Life Enjoyment and Satisfaction Questionnaire (Q-LES-Q). DUL or placebo (for one treatment cycle) was administrated for up to three menstrual cycles. The response rate to treatment $(\geq 50 \%$ reduction in total DRSP scores from baseline to endpoint) was $65 \%$ (intention-totreat [ITT] population 13/20); the patients also experienced a significant reduction of functional impairment associated with premenstrual symptoms. Common and generally transient side effects at the first treatment cycle were gastrointestinal disturbances and decreased appetite, whereas headaches, decreased libido, insomnia, and sweating persisted throughout the treatment cycles (three patients dropped out for persistent, although not serious, adverse effects).

\section{Use of Duloxetine in Other Psychiatric Disorders}

The efficacy of DUL in patients with psychiatric disorders other than mood disorders has been evaluated in 12 clinical trials (Table 3).

\section{Obsessive-Compulsive Disorder}

To date, the use of DUL in the treatment of patients with OCD has been assessed in one open-label study and one doubleblind, controlled augmentation trial. The 17-week, open-label trial by Dougherty et al. (36) evaluated the efficacy and safety of DUL on OCD symptom severity as assessed by the YaleBrown Obsessive Compulsive Scale (YBOCS) and CGI (primary outcome measures); psychometric examination also included BDI, Beck Anxiety Scale, and the Q-LES-Q (secondary and tertiary outcome measures). The total sample was formed by 20 OCD patients ( 12 completers); results evidenced that, of the 12 completers, 7 (58.3\%) were full responders and 3 (25\%) were nonresponders according to primary outcome measures; DUL at the dose range of 60 to $120 \mathrm{mg} /$ day was effective for reducing YBOCS total score (mean $\pm \mathrm{SD}=28.33 \pm 4.66$ at baseline, $18.5 \pm$ 7.98 at endpoint; $P<0.001$ ) and CGI score (mean $\pm \mathrm{SD}=4.00 \pm$ 0 at baseline, $2.17 \pm 0.72$ at endpoint; $P<0.001)$. Five participants out of 12 (40\%) discontinued the study because of adverse events, and two patients required a reduction in dosage due to adverse events. The most common unwanted effects were nausea $(50 \%$ of subjects), fatigue (41.2\%), sexual dysfunction (23.1\%), and headache (11.1\%); no serious adverse events occurred.

The 8-week randomized controlled, double-blind study (37) assessed the efficacy of adjunct DUL or sertraline in patients with resistant OCD treated with SSRIs or fluvoxamine. Forty-six OCD patients who had failed an average of two SSRI trials of adequate dose and duration before the start of the study were randomly allocated to receive, under a double-blind condition, DUL (dose range $=20-60 \mathrm{mg} /$ day; mean dosage $=44.4 \mathrm{mg}$ / day; $\mathrm{n}=24$ ) or sertraline (dose range $=50-200 \mathrm{mg} /$ day; mean dose $=123.8 \mathrm{mg} /$ day; $\mathrm{n}=22$ ). The primary outcome measure was the YBOCS; the efficacy index of CGI was used at the end of the study. At endpoint, both DUL and sertraline were effective in reducing OCD symptoms, as assessed by YBOCS mean total score reduction $(33.0 \%$ for DUL and $34.5 \%$ for sertraline); 15 DUL-treated patients and 13 sertraline-assuming subjects were considered responders. Six patients in the DUL group and five patients in the sertraline group dropped out because of unwanted side effects; the more common were gastrointestinal disturbances, followed by headache and sexual disturbances.

\section{Panic Disorder}

A single, 8-week, open-label, flexible-dose study (38) has evaluated the efficacy of DUL (dose range $=30-120 \mathrm{mg} /$ day; mean \pm SD dose at endpoint $=94 \pm 25 \mathrm{mg} /$ day) in 15 patients (12 completers) with PD. Primary outcome measure was the Panic Disorder Severity Scale; secondary measures included panic attack frequency as measured by the Panic Attack Scale and the CGI-S. Results suggested that DUL was associated with a significant improvement in symptom severity (all primary and secondary measures $=P<0.01$ ), with eight patients not experiencing full panic attacks in the past 2 weeks and four achieving full remission. The most common side effects were nausea, sedation, and sexual dysfunction. DUL was generally well tolerated, with only two patients discontinuing the drug for side effects both in the first week on medication (one due to insomnia and loss of appetite, one for worsened depression).

\section{Posttraumatic Stress Disorder}

To date, the efficacy and tolerability of DUL in PTSD have been evaluated in a 12-week open-label trial on a sample of 20 (15 completers) military veterans affected by PTSD (39). Primary efficacy measure was the Clinician-Administered PTSD Scale (CAPS), assessing the severity of PTSD symptomatology, whereas secondary measures included the HDRS. Duloxetine (mean daily dose $=81 \mathrm{mg} /$ day) was effective in reducing PTSD and depressive symptoms, as assessed by changes in primary and secondary outcome measures, with nine participants (45\%) classified as responders, defined by $20 \%$ or greater improvement on CAPS total score. Of the total number of five subjects who dropped out from the trial, three were due to side effects (constipation, diarrhea, and nausea were the most common); two subjects developed tachycardia, and one withdrew from the trial for this problem.

\section{Eating Disorders}

The efficacy of DUL on binge-eating disorders (BEDs) has been evaluated in trials, one open-label and one placebo-controlled. A preliminary, 12-week, open-label study (40) tested the efficacy of flexible doses of DUL (dose range $=60-120 \mathrm{mg} /$ day) in a sample of 45 obese outpatients who satisfied the full criteria for BED ( $\mathrm{n}=22)$ and in subjects $(\mathrm{n}=23)$ with subthreshold binge eating, characterized by high eating impulsivity. Number of binge-eating episodes per week and scores on the Binge Eating Scale (BES) 
were the primary outcome measures; effect on weight, body mass index (BMI), depressive symptoms (BDI score), and CGI-S were the secondary outcome measures. The 31 completers reported a significant reduction in BES scores, number of binges, weight, BMI, and BDI scores, as well as in CGI-S scores; 14 subjects dropped out for reasons unrelated to side effects. DUL was generally tolerated: most frequent side effects were nausea and insomnia. A double-blind study of duloxetine versus placebo was carried out in 2011, involving 40 subjects with BED comorbid with depressive disorders (41). The administration of DUL started from the dose of $30 \mathrm{mg} /$ day for the first week, to $60 \mathrm{mg} /$ day for the second week, possibly $90 \mathrm{mg} /$ day from the fourth week, and $120 \mathrm{mg} /$ day from the sixth week, when positive effects were not reached, and DUL was well tolerated. Endpoints were the intensity and the number of episodes of binge eating, BMI, and depressive symptoms. After the end of the trial, DUL was proven to be effective in ameliorating the selected parameters.

\section{Schizophrenia}

The first report of DUL add-on in schizophrenia was a doubleblind, 16-week, randomized trial on a sample of 40 (33 completers) schizophrenia patients classified as partial responders to clozapine according to a score $\geq 25$ on the Brief Psychiatric Rating Scale (BPRS). DUL, at the dose of $60 \mathrm{mg} /$ day, was proven effective in improving negative and general psychopathology symptoms, as documented by the reduction of negative subscale scores of the Positive and Negative Syndrome Scale (PANSS) and BPRS scores, respectively. Cognitive functioning, as measured by Stroop test, verbal fluency, and Wisconsin Card Sorting Test, did not change during DUL treatment. Combined therapy of DUL and clozapine was generally well tolerated, with gastrointestinal symptoms and headache as the most commonly reported side effects; $15 \%$ of the dropouts were in the treated group and $20 \%$ in the control group (42). More recently, an 8-week, randomized, double-blind, placebo-controlled, parallel-group trial aimed at evaluating DUL $60 \mathrm{mg} /$ day added to risperidone (dose range = 4-6 mg/day) for treating negative symptoms in 64 schizophrenia patients (43). DUL was effective in improving negative and general psychopathology symptoms of schizophrenia, as shown by reductions in PANSS total and subscales scores. Adverse events did not differ between DUL and placebo groups.

\section{Premature Ejaculation}

Two studies have evaluated DUL efficacy and safety in the treatment of PE. In a 12-week study (44), 20 subjects who had been diagnosed with PE were randomly allocated to receive DUL (up to $80 \mathrm{mg} /$ day; $\mathrm{n}=10$ subjects) or placebo ( $\mathrm{n}=10$ subjects). The intravaginal ejaculation latency time (IELT), defined as the duration between vaginal intromission and ejaculation, was the outcome measure. All 20 participants completed the treatment. At endpoint, the IELT significantly increased in DUL group but not in placebo group (mean time \pm SD DUL vs. placebo = $129.34 \pm 67.58$ vs. $38.61 \pm 16.99 ; P<0.001)$. Common side effects were nausea and dry mouth for three patients in the active group and excessive sweating for one patient from placebo group; no patient dropped out from each treatment group because of adverse events. A more recent 4 -week study (45) has examined the efficacy and tolerability of DUL versus paroxetine in PE in a sample of 80 patients randomly distributed to receive DUL $40 \mathrm{mg} /$ day $(\mathrm{N}=40$; mean \pm SD baseline IELT $=55 \pm 5.8 \mathrm{~s})$ or paroxetine $20 \mathrm{mg} /$ day $(\mathrm{N}=40$; mean $\pm \mathrm{SD}$ baseline IELT = 54.3 $\pm 5.9 \mathrm{~s})$. The International Index of Erectile Function Questionnaire, IELT, and Premature Ejaculation Profile, assessing personal and interpersonal distress related to ejaculation, perceived control over ejaculation, and satisfaction with sexual intercourse, were recorded before and after treatment. Both DUL and paroxetine were effective in increasing IELT from baseline to endpoint (117\% in the DUL, $P<0.001$, and $126 \%$ in the paroxetine group, $P<0.001$; no statistical differences between the two groups in terms of IELT increase were found). Both treatments were also effective in decreasing mean scores for personal distress and interpersonal difficulty related to ejaculation $(P<0.001)$. Both treatments were well tolerated, and none of the patients withdrew from the study; the most common side effects were nausea $(\mathrm{N}=10)$ and headache $(\mathrm{N}=5)$ in DUL-treated patients, sedation $(\mathrm{N}=10)$, nausea $(\mathrm{N}=10)$, and asthenia $(\mathrm{N}=5)$ in the paroxetine group.

\section{Adult Attention-Deficit/Hyperactivity Disorder}

A 6-week, randomized, double-blind, placebo-controlled trial (46) has explored the efficacy and safety of DUL at the daily dose of $60 \mathrm{mg}$ in a sample of 30 adults (24 completers) with ADHD. Primary efficacy measures were the Conners' Adult ADHD Rating Scale-Investigator Report: Screening Version (CAARSInv : SV), the CGI-S, and the CGI-I. At the end of the trial, no group differences were found on CAARS-Inv : SV, whereas significant improvements were seen in DUL group in CGI-S (3.00 vs. 4.07 for placebo, $P<0.001)$ and CGI-I (2.89 vs. 4.00 at week $6, P<0.001)$ scores. Main side effects of DUL treatment were nausea, xerostomia, headache, increased anxiety, constipation, and blurred vision; during the first week of treatment, there were six dropouts in the DUL group due to unwanted effects.

\section{Borderline Personality Disorder}

The efficacy and tolerability of DUL for treating symptomatic clusters of BPD has been evaluated in a 12-week, open-label trial (47) including a sample of 18 patients ( 14 completers: 9 females and 5 males, with 4 dropouts due to noncompliance) treated with DUL, $60 \mathrm{mg} /$ day; no other psychotropic drug or psychological intervention was allowed during the trial. Psychodiagnostic evaluation included a semistructured clinical interview assessing frequency and severity of BPD symptoms (BPDSI), the CGI$S$, and rating scales for depression (HDRS), anxiety (HARS), general psychopathology (BPRS), social and occupational functioning (Social Occupational Functioning Assessment Scale [SOFAS]), and somatization (Hopkins Symptom Checklist-90 Somatization Subscale [HSCL-90 SOM]). Results showed statistically significant improvements in three BPDSI items: impulsivity $(P=0.028)$, outbursts of anger $(P=0.0005)$, and affective instability $(P=0.001)$ and total score $(P=0.001)$, CGI-S mean score $(P=0.002)$, BPRS mean score $(P=0.001)$, HAM-D mean score $(P=0.035)$, SOFAS mean score $(P=0.0005)$, and HSCL-90 SOM mean score $(P=0.0005)$. DUL treatment was generally well tolerated, and the four dropouts were unrelated 
to tolerability. Most common adverse effects were nausea and headache, gastrointestinal symptoms, dizziness, and insomnia.

\section{DISCUSSION}

The prescription of antidepressants for psychiatric disorders other than MDD and GAD is a common practice. The evidence here reviewed suggests that DUL may be a potential treatment for treating different clusters of psychiatric symptoms.

Regarding the spectrum of mood disorders, the findings from the examined studies highlighted the efficacy and tolerability of DUL, with response rates ranging from $53 \%$ to $>80 \%$. DUL treatment significantly improved, with a satisfactory tolerability profile, dysthymia in adults (29), and pure DD of older adults (30), a form of dysthymia with typical onset in late life, characterized by the lack of psychiatric comorbidities and by a worse response to treatments (48). In PDD, DUL resulted effective in the shortterm treatment (31) and for maintaining symptom improvement over time, with a positive impact on more general aspects of functioning and on social adjustment (32).

In $\mathrm{SAD}$, promising results have been obtained from a single, small, open-label, short-term study (33); consequently, it is difficult to draw any conclusions about the real efficacy and safety of DUL in the longer term and in larger samples of SADaffected patients. The available studies $(34,35)$ support evidence on the efficacy and tolerability of DUL as monotherapy in the treatment of PMDD, highlighting significant improvements in the core symptoms of irritability, affective lability, tension, depressed mood, and functional impairment; nevertheless, these results should be considered as preliminary, due to methodological limitations.

Concerning psychiatric conditions not belonging to the spectrum of mood disorders, uncertain results have been found. Positive results emerged for PD, schizophrenia, and borderline personality disorder. It seems almost intuitive that $\mathrm{PD}$, being an anxiety disorder, can benefit from treatment with DUL, although the evidence comes from a single, open-label, and underpowered trial (38). In schizophrenia, results from two randomized, doubleblind, placebo-controlled trials $(42,43)$ have documented the significant effect of DUL as add-on treatment on negative and general psychopathological symptoms. Antidepressant drugs are commonly used as an augmentation strategy to enhance the efficacy of antipsychotics (APs) $(49,50,51)$, although it must be kept in mind that such strategy is not supported by robust scientific evidence regarding efficacy and safety and that it may substantially increase the risk of developing drug interactions and adverse events. In BPD, DUL improved several core symptoms of the disorder, such as anger outbursts, affective instability, and impulsivity; congruently with a possible effect also on the affective dimension, this finding indicates a potential use of DUL in at least a subgroup of BPD patients prominently exhibiting these clusters of features (47).

DUL resulted moderately effective in treating PTSD, with a response rate $<50 \%$ (39); this result is too specific and scarcely generalizable, since it is referred to a special population (military veterans). However, it should be noticed that the disorder is characterized by generally high nonresponse rates across treatment strategies, which recommended medications vary across different guidelines and that both first- and second-line treatments mostly act by reducing expression of PTSD symptoms, rather than providing remission and relapse prevention (52).

Conflicting results emerged in OCD, eating disorders, and PE $(36,37,38,40,44,45)$. Possible reasons for these discrepancies in outcomes may derive from differences in study design and methodology, such as open-label, uncontrolled versus randomized, double-blind designs, and from differences in doses and treatment intervals. Furthermore, only few studies applied the ITT analysis for the data analyses, and the plausible effect of not accounting for dropouts with ITT data must be taken into account.

Findings from the double-blind, randomized, placebocontrolled trial in adult ADHD are quite difficult to interpret, since no statistically significant differences between DUL and placebo on primary measure for ADHD symptoms (CAARS-Inv : SV) were found; nevertheless, the authors stressed positive changes in general clinical and in secondary measures, concluding that DUL may represent a valuable treatment option in ADHD (46).

In all reviewed studies, DUL treatment was generally well tolerated; consistently through all trials, most reported adverse events were consistent with the known safety profile of duloxetine and included gastrointestinal disturbances, headache, sedation, dry mouth, sexual dysfunctions, sweating, and insomnia, mainly in the mild-to-moderate range. Nevertheless, the data showed that adverse effects and discontinuations due to adverse effects were not uncommon.

In terms of response and overall acceptability, and also due to the relative scarcity of head-to-head comparisons with other antidepressants, duloxetine has not been recommended as a routine first-line acute treatment for major depression (53). Nevertheless, the drug has been proven safe and effective for improving core emotional symptoms and general functioning in $\operatorname{MDD}(54,55)$ and psychic and somatic anxiety symptoms in $\operatorname{GAD}(56,57)$; in prospective studies of efficacy, duloxetine has been evaluated employing the remission concept (getting the patient asymptomatic), rather than the response concept (getting the patient $50 \%$ better), and with a focus on recovery, which includes both clinical and functional remissions.

\section{CONCLUSIONS}

Duloxetine is a dual-acting agent with a well-established use in MDD and GAD and approved for several clinical conditions other than psychiatric disorders, such as urinary incontinence, neuropathic pain, and FM. Its most significant feature relies on the double way of action through the selective blockades of serotonin and NE reuptake in the central nervous system with scarce or lack of affinity for muscarinic, histamine 1 and $\beta 1$ adrenergic receptors; therapeutic benefits are usually achieved at the dose of $60 \mathrm{mg} / \mathrm{day}$, and the drug is generally well tolerated, with transient and/or minor adverse reactions.

Regarding the use of duloxetine in other psychiatric disorders, the evidence here reviewed suggests that duloxetine may be an effective treatment for mood spectrum disorders, with relatively high rates of response and remission, $\mathrm{PD}$, several symptom clusters of borderline 
personality, and as add-on drug in schizophrenia with the aim of addressing negative symptoms. Modest, inconsistent, or conflicting results have been found for the potential efficacy of duloxetine in OCD, PTSD, eating, and sexual disorders. However, apart from sporadic randomized, double-blind, controlled studies, most of the evidence comes from several interesting open-label studies, although limited by short trial duration, small sample sizes, and by the lack of control groups; furthermore, the long-term efficacy of duloxetine has not yet been investigated. Information on the efficacy and safety of duloxetine in special populations such as adolescents and elderly patients and in potentially at-risk samples of subjects with impaired organ function is still limited. This relative paucity of data does not allow drawing firm conclusions on the potential role of duloxetine in the treatment of psychiatric disorders other than MDD and GAD; further randomized, placebo-controlled studies of

\section{REFERENCES}

1. Sansone, RA, and Sansone, LA. Serotonin norepinephrine reuptake inhibitors: a pharmacological comparison. Innov Clin Neurosci (2014) 11:37-42.

2. Farshchian, N, Alavi, A, Heydarheydari, S, and Moradian, N. Comparative study of the effects of venlafaxine and duloxetine on chemotherapy-induced peripheral neuropathy. Cancer Chemother Pharmacol (2018) 82:787-93. doi: 10.1007/s00280-018-3664-y

3. Bedin, A, Caldart Bedin, RA, Vieira, JE, and Ashmawi, HA. Duloxetine as an analgesic reduces opioid consumption after spine surgery: a randomized, double-blind, controlled study. Clin J Pain (2017) 33:865-9. doi: 10.1097/ AJP.0000000000000471

4. Bymaster, FP, Dreshfield-Ahmad, LJ, Threlkeld, PG, Shaw, JL, Thompson, L, Nelson, DL, et al. Comparative affinity of duloxetine and venlafaxine for serotonin and norepinephrine transporters in vitro and in vivo, human serotonin receptor subtypes, and other neuronal receptors. Neuropsychopharmacol (2001) 25:871-80. doi: 10.1016/S0893-133X(01) 00298-6

5. Vaishnavi, SN, Nemeroff, CB, Plott, SJ, Rao, SG, Kranzler, J, and Owens, MJ. Milnacipran: a comparative analysis of human monoamine uptake and transporter binding affinity. Biol Psychiatry (2004) 55:320-2. doi: 10.1016/j. biopsych.2003.07.006

6. Deecher, DC, Beyer, CE, Johnston, G, Bray, J, Shah, S, Abou-Gharbia, M, et al. Desvenlafaxine succinate: a new serotonin and norepinephrine reuptake inhibitor. J Pharmacol Exp Ther (2006) 318:657-65. doi: 10.1124/jpet.106.103382

7. Bruno, A, Morabito, P, Spina, E, and Muscatello, MR. The role of levomilnacipran in the management of major depressive disorder: a comprehensive review. Curr Neuropharmacol (2016) 14:191-9. doi: 10.2174/ 1570159X14666151117122458

8. Karpa, KD, Cavanaugh, JE, and Lakoski, JM. Duloxetine pharmacology: profile of a dual monoamine modulator. CNS Drug Rev (2002) 8:361-76. doi: 10.1111/j.1527-3458.2002.tb00234.x

9. Torres-Sanchez, S, Perez-Caballero, L, Mico, JA, Elorza, J, and Berrocoso, E. Preclinical discovery of duloxetine for the treatment of depression. Expert Opin Drug Discov (2012) 7:745-55. doi: 10.1517/17460441.2012.693912

10. De La Garza, R, Jentsch, JD, Verrico, CD, and Roth, RH. Adaptation of monoaminergic responses to phencyclidine in nucleus accumbens and prefrontal cortex following repeated treatment with fluoxetine or imipramine. Brain Res (2002) 958:20-7. doi: 10.1016/S0006-8993(02)03772-1

11. Calabrese, F, Molteni, R, Cattaneo, A, Macchi, F, Racagni, G, Gennarelli, M, et al. Long-term duloxetine treatment normalizes altered brain-derived neurotrophic factor expression in serotonin transporter knockout rats through the modulation of specific neurotrophin isoforms. Mol Pharmacol (2010) 77:846-53. doi: 10.1124/mol.109.063081

12. Russo-Neustadt, AA, Alejandre, H, Garcia, C, Ivy, AS, and Chen, MJ. Hippocampal brain-derived neurotrophic factor expression following treatment adequate duration on larger samples are needed for better defining the whole therapeutic potential of this antidepressant.

\section{AUTHOR CONTRIBUTIONS}

$\mathrm{MM}, \mathrm{RZ}, \mathrm{ES}$, and $\mathrm{AB}$ designed the study and supervised the methods and procedures, the various drafts, and the final version of the manuscript. PM and SL performed the initial search, independently reviewed and selected the references based on the inclusion and exclusion criteria, and clarified any disputes in the presence of a third expert reviewer (MM). GP, CC, and FB managed the literature searches and wrote the first drafts of the manuscript. All authors contributed to and have approved the final manuscript.

with reboxetine, citalopram, and physical exercise. Neuropsychopharmacol (2004) 29:2189-99. doi: 10.1038/sj.npp.1300514

13. Molteni, R, Calabrese, F, Mancini, M, Racagni, G, and Riva, MA. Basal and stress-induced modulation of activity-regulated cytoskeletal associated protein (Arc) in the rat brain following duloxetine treatment. Psychopharmacology (Berl) (2008) 201:285-92. doi: 10.1007/s00213-008-1276-7

14. Millan, MJ. Descending control of pain. Prog Neurobiol (2002) 66:355-474. doi: 10.1016/S0301-0082(02)00009-6

15. Bomholt, SF, Mikkelsen, JD, and Blackburn-Munro, G. Antinociceptive effects of the antidepressants amitriptyline, duloxetine, mirtazapine and citalopram in animal models of acute, persistent and neuropathic pain. Neuropharmacology (2005) 48:252-63. doi: 10.1016/j.neuropharm.2004.09.012

16. Thor, KB. Serotonin and norepinephrine involvement in efferent pathways to the urethral rhabdosphincter: implications for treating stress urinary incontinence. Urology (2003) 62:3-9. doi: 10.1016/S0090-4295(03)00754-4

17. Lantz, RJ, Gillespie, TA, Rash, TJ, Kuo, F, Skinner, M, Kuan, H-Y, et al. Metabolism, excretion, and pharmacokinetics of duloxetine in healthy human subjects. Drug Metab Dispos (2003) 31:1142-50. doi: 10.1124/dmd. 31.9.1142

18. Sharma, A, Goldberg, MJ, and Cerimele, BJ. Pharmacokinetics and safety of duloxetine, a dual-serotonin and norepinephrine reuptake inhibitor. J Clin Pharmacol (2000) 40:161-7. doi: 10.1177/00912700022008810

19. Spina, E, Santoro, V, and D'Arrigo, C. Clinically relevant pharmacokinetic drug interactions with second-generation antidepressants: an update. Clin Ther (2008) 30:1206-27. doi: 10.1016/S0149-2918(08)80047-1

20. Whitmyer, VG, Dunner, DL, Kornstein, SG, Meyers, AL, Mallinckrodt, CH, Wohlreich, MM, et al. Greist JH. A comparison of initial duloxetine dosing strategies in patients with major depressive disorder. J Clin Psychiatry (2007) 68:1921-30. doi: 10.4088/JCP.v68n1213

21. Ball, SG, Desaiah, D, Zhang, Q, Thase, ME, and Perahia, DGS. Efficacy and safety of duloxetine $60 \mathrm{mg}$ once daily in major depressive disorder: a review with expert commentary. Drugs Context (2013) 2013:212245. doi: 10.7573/ dic. 212245

22. Dhillon, S. Duloxetine: a review of its use in the management of major depressive disorder in older adults. Drugs Aging (2013) 30:59-79. doi: 10.1007/s40266-012-0040-1

23. Thase, ME, Tran, PV, Wiltse, C, Pangallo, BA, Mallinckrodt, C, and Detke, MJ. Cardiovascular profile of duloxetine, a dual reuptake inhibitor of serotonin and norepinephrine. J Clin Psychopharmacol (2005) 25:132-40. doi: 10.1097/01.jcp.0000155815.44338.95

24. Acharya, N, Rosen, AS, Polzer, JP, D'Souza, DN, Perahia, DG, Cavazzoni, PA, et al. Duloxetine: meta-analyses of suicidal behaviors and ideation in clinical trials for major depressive disorder. J Clin Psychopharmacol (2006) 26:58794. doi: 10.1097/01.jcp.0000246216.26400.db

25. Reference ID: 2860327. Cymbalta - Highlights of Prescribing Information. FDA Approved Drug Products. (2010). 
26. Jones, CM, Mack, KA, and Paulozzi, LJ. Pharmaceutical overdose deaths, United States, 2010. JAMA (2013) 309:657-9. doi: 10.1001/jama.2013.272

27. Fava, GA, Benasi, G, Lucente, M, Offidani, E, Cosci, F, and Guidi, J. Withdrawal symptoms after serotonin-noradrenaline reuptake inhibitor discontinuation: systematic review. Psychother Psychosom (2018) 87:195203. doi: $10.1159 / 000491524$

28. Moher, D, Liberati, A, Tetzlaff, J, and Altman, DG. PRISMA Group. Preferred reporting items for systematic reviews and meta-analyses: the PRISMA statement. PLoS Med (2009) 6:e1000097. doi: 10.1371/journal.pmed.1000097

29. Koran, LM, Aboujaoude, EN, and Gamel, NN. Duloxetine treatment of dysthymia and double depression: an open-label trial. J Clin Psychiatry (2007) 68:761-5. doi: 10.4088/JCP.v68n0514

30. Kerner, N, D’Antonio, K, Pelton, GH, Salcedo, E, Ferrar, J, Roose, SP, et al. An open treatment trial of duloxetine in elderly patients with dysthymic disorder. SAGE Open Med (2014) 2:1-6. doi: 10.1177/2050312114533536

31. Hellerstein, DJ, Stewart, JW, McGrath, PJ, Deliyannides, DA, Batchelder, ST, Black, SR, et al. A randomized controlled trial of duloxetine versus placebo in the treatment of nonmajor chronic depression. J Clin Psychiatry (2012) 73:984-91. doi: 10.4088/JCP.11m07230

32. Hellerstein, DJ, Hunnicutt-Ferguson, K, Stewart, JW, McGrath, PJ, Keller, S, Peterson, BS, et al. Do social functioning and symptoms improve with continuation antidepressant treatment of persistent depressive disorder? An observational study. J Affect Disord (2017) 210:258-64. doi: 10.1016/j. jad.2016.12.026

33. Pjrek, E, Willeit, M, Praschak-Rieder, N, Konstantinidis, A, Semlitsch, HV, Kasper, S, et al. Treatment of seasonal affective disorder with duloxetine: an openlabel study. Pharmacopsychiatry (2008) 41:100-5. doi: 10.1055/s-2008-1058103

34. Mazza, M, Harnic, D, Catalano, V, Janiri, L, and Bria, P. Duloxetine for premenstrual dysphoric disorder: a pilot study. Expert Opin Pharmacother (2008) 9:517-21. doi: 10.1517/14656566.9.4.517

35. Ramos, MG, Hara, C, and Rocha, FL. Duloxetine treatment for women with premenstrual dysphoric disorder: a single-blind trial. Int $J$ Neuropsychopharmacol (2009) 12:1081-8. doi: 10.1017/S1461145709000066

36. Dougherty, DD, Corse, AK, Chou, T, Duffy, A, Arulpragasam, AR, Deckersbach, T, et al. Open-label study of duloxetine for the treatment of obsessive-compulsive disorder. Int J Neuropsychopharmacol (2015) 18:1-4. doi: 10.1093/ijnp/pyu062

37. Mowla, A, Boostani, $\mathrm{S}$, and Dastgheib, SA. Duloxetine augmentation in resistant obsessive-compulsive disorder: a double-blind controlled clinical trial. J Clin Psychopharmacol (2016) 36:720-3. doi: 10.1097/JCP.0000000000000592

38. Simon, NM, Kaufman, RE, Hoge, EA, Worthington, JJ, Herlands, NN, Owens, ME, et al. Open-label support for duloxetine for the treatment of panic disorder. CNS Neurosci Ther (2009) 15:19-23. doi: 10.1111/j.1755-5949.2008.00076.x

39. Villarreal, G, Cañive, JM, Calais, LA, Toney, G, and Smith, AK. Duloxetine in military posttraumatic stress disorder. Psychopharmacol Bull (2010) 43:26-34.

40. Leombruni, P, Lavagnino, L, Gastaldi, F, Vasile, A, and Fassino, S. Duloxetine in obese binge eater outpatients: preliminary results from a 12-week open trial. Hum Psychopharmacol (2009) 24:483-8. doi: 10.1002/hup.1040

41. Guerdjikova, AI, McElroy, SL, Winstanley, EL, Nelson, EB, Mori, N, McCoy, J, et al. Duloxetine in the treatment of binge eating disorder with depressive disorders: a placebo-controlled trial. Int J Eat Disord (2012) 45:281-9. doi: 10.1002/eat.20946

42. Mico', U, Bruno, A, Pandolfo, G, Maria Romeo, V, Mallamace, D, D’Arrigo, C, et al. Duloxetine as adjunctive treatment to clozapine in patients with schizophrenia: a randomized, placebo-controlled trial. Int Clin Psychopharmacol (2011) 26:303-10. doi: 10.1097/YIC.0b013e32834bbc0d

43. Nikbakhat, M-R, Arabzadeh, S, Zeinoddini, A, Khalili, Z, Rezaei, F, Mohammadinejad, P, et al. Duloxetine add-on to risperidone for treatment of negative symptoms in patients with stable schizophrenia: randomized double-blind placebo-controlled study. Pharmacopsychiatry (2016) 49:1629. doi: 10.1055/s-0042-101557

44. Athanasios, Z, Polyanthi, P, and George, K. The efficacy of duloxetine in the treatment of premature ejaculation. Int Urol Nephrol (2007) 39:115-8. doi: $10.1007 /$ s11255-006-6659-2
45. Ozcan, L, Polat, EC, Otunctemur, A, and Ozbek, E. Duloxetine, dual serotonin and norepinephrine reuptake inhibitor, versus paroxetine, selective serotonin reuptake inhibitor, in the treatment for premature ejaculation. Int Urol Nephrol (2015) 47:283-7. doi: 10.1007/s11255-014-0905-9

46. Bilodeau, M, Simon, T, Beauchamp, MH, Lespérance, P, Dubreucq, S, Dorée, J-P, et al. Duloxetine in adults with ADHD: a randomized, placebo-controlled pilot study. J Atten Disord (2014) 18:169-75. doi: 10.1177/1087054712443157

47. Bellino, S, Paradiso, E, Bozzatello, P, and Bogetto, F. Efficacy and tolerability of duloxetine in the treatment of patients with borderline personality disorder: a pilot study. J Psychopharmacol (Oxford) (2010) 24:333-9. doi: $10.1177 / 0269881108095715$

48. Devanand, DP, Adorno, E, Cheng, J, Burt, T, Pelton, GHGH, Roose, SPSP, et al. Late onset dysthymic disorder and major depression differ from early onset dysthymic disorder and major depression in elderly outpatients. J Affect Disord (2004) 78:259-67. doi: 10.1016/S0165-0327(02)00307-5

49. Bruno, A, Zoccali, RA, Abenavoli, E, Pandolfo, G, Scimeca, G, Spina, E, et al. Augmentation of clozapine with agomelatine in partial-responder schizophrenia: a 16-week, open-label, uncontrolled pilot study. J Clin Psychopharmacol (2014) 34:491-4. doi: 10.1097/JCP.0000000000000157

50. Vernon, JA, Grudnikoff, E, Seidman, AJ, Frazier, TW, Vemulapalli, MS, Pareek, P, et al. Antidepressants for cognitive impairment in schizophrenia-a systematic review and meta-analysis. Schizophr Res (2014) 159:385-94. doi: 10.1016/j.schres.2014.08.015

51. Bruno, A, Zoccali, R, Bellinghieri, PM, Pandolfo, G, De Fazio, P, Spina, E, et al. Reboxetine adjuvant therapy in patients with schizophrenia showing a suboptimal response to clozapine: a 12-week, open-label, pilot study. J Clin Psychopharmacol (2014) 34:620-3. doi: 10.1097/JCP.0000000000000196

52. Lee, DJ, Schnitzlein, CW, Wolf, JP, Vythilingam, M, Rasmusson, AM, and hoge, cw. psychotherapy versus pharmacotherapy for posttraumatic stress disorder: systemic review and meta-analyses to determine first-line treatments. Depress Anxiety (2016) 33:792-806. doi: 10.1002/da.22511

53. Cipriani, A, Koesters, M, Furukawa, TA, Nosè, M, Purgato, M, Omori, IM, et al. Duloxetine versus other anti-depressive agents for depression. Cochrane Database Syst Rev (2012) 10:CD00533. doi: 10.1002/14651858.CD006533

54. Huang, J, Wang, Y, Chen, J, Zhang, Y, Yuan, Z, Yue, L, et al. Clinical outcomes of patients with major depressive disorder treated with either duloxetine, escitalopram, fluoxetine, paroxetine, or sertraline. Neuropsychiatr Dis Treat (2018) 14:2473-84. doi: 10.2147/NDT.S159800

55. Andrade, C. Relative efficacy and acceptability of antidepressant drugs in adults with major depressive disorder: commentary on a network metaAnalysis. J Clin Psychiatry (2018) 79:18f12254. doi: 10.4088/JCP.18f12254

56. Zhang, Y, Huang, G, Yang, S, Liang, W, Zhang, L, and Wang, C. Duloxetine in treating generalized anxiety disorder in adults: A meta-analysis of published randomized, double-blind, placebo-controlled trials. Asia Pac Psychiatry (2016) 8:215-25. doi: 10.1111/appy.12203

57. Li, X, Zhu, L, Zhou, C, Liu, J, Du, H, Wang, C, et al. Efficacy and tolerability of short-term duloxetine treatment in adults with generalized anxiety disorder: a meta-analysis. PLoS One (2018) 13:e0194501. doi: 10.1371/ journal.pone.0194501

Conflict of Interest: ES has previously received honoraria for speaking and consultation from AstraZeneca, Boehringer Ingelheim, Eli Lilly, Janssen, Lundbeck, and Pfizer.

The remaining authors declare that the research was conducted in the absence of any commercial or financial relationships that could be construed as a potential conflict of interest.

Copyright $\odot 2019$ Muscatello, Zoccali, Pandolfo, Mangano, Lorusso, Cedro, Battaglia, Spina and Bruno. This is an open-access article distributed under the terms of the Creative Commons Attribution License (CC BY). The use, distribution or reproduction in other forums is permitted, provided the original author(s) and the copyright owner(s) are credited and that the original publication in this journal is cited, in accordance with accepted academic practice. No use, distribution or reproduction is permitted which does not comply with these terms. 